\title{
New insights into the population genetics of partially clonal organisms: when seagrass data meet theoretical expectations
}

\author{
Arnaud-Haond Sophie ${ }^{1,{ }^{*}}$, Stoeckel Solenn ${ }^{2}$, Bailleul Diane ${ }^{1}$
}

\author{
${ }^{1}$ MARBEC Université de Montpellier, Ifremer, IRD, CNRS Laboratory Environnements-Ressources \\ Ifremer Bd Jean Monnet BP 171, Sète 34203 ,France \\ 2 IGEPP INRAE, Institut Agro Univ Rennes 35653 Le Rheu ,France \\ * Corresponding author : Sophie Arnaud-Haond, email address : $\underline{\text { sarnaud@ifremer.fr }}$
}

\begin{abstract}
:
Seagrass meadows are among the most important coastal ecosystems in terms of both spatial extent and ecosystem services, but they are also declining worldwide. Understanding the drivers of seagrass meadow dynamics is essential for designing sound management, conservation, and restoration strategies. However, poor knowledge of the effect of clonality on the population genetics of natural populations severely limits our understanding of the dynamics and connectivity of meadows. Recent modeling approaches have described the expected distributions of genotypic and genetic descriptors under increasing clonal rates, which may help us better understand and interpret population genetics data obtained for partial asexuals. Here, in light of these recent theoretical developments, we revisited population genetics data for 165 meadows of four seagrass species. Contrasting shoot lifespan and rhizome turnover led to the prediction that the influence of asexual reproduction would increase along a gradient from Zostera noltii to Zostera marina, Cymodocea nodosa and Posidonia oceanica, with increasing departure from Hardy-Weinberg equilibrium ( $F$ is), mostly towards heterozygote excess, and decreasing genotypic richness $(R)$. This meta-analysis provides a nested validation of this hypothesis at both the species and meadow scales through a significant relationship between $F$ is and $R$ within each species. By empirically demonstrating the theoretical expectations derived from recent modeling approaches, this work calls for the use of Hardy-Weinberg equilibrium ( $F$ is) rather than only the strongly sampling-sensitive $R$ to assess the importance of clonal reproduction (c), at least when the impact of selfing on $\mathrm{F}$ is can be neglected. The results also emphasize the need to revise our appraisal of the extent of clonality and its influence on the dynamics, connectivity and evolutionary trajectory of partial asexuals in general, including in seagrass meadows, to develop the most accurate management strategies.
\end{abstract}




\section{Introduction}

Clonality is a life history trait spread across the Tree of Life (Halkett et al., 2005) that characterizes the species forming the basis of most important terrestrial and marine ecosystems. The drastic disappearance of many ecosystems engineered by partially clonal species (Carlsson Callaghan, 1994; Carpenter et al., 2008; Polidoro et al., 2010; Waycott et al., 2009) emphasizes the need to identify the drivers and life history traits underlying demographic fluctuations associated with range contractions, shifts, or expansions (Aitken et al., 2008; Callaghan et al., 1992; Cornelissen et al., 2014; Pecuchet et al., 2018; Yu et al., 2016). Population genetics studies can provide essential indirect evidence of these drivers and life history traits. However, the lack of clear theoretical predictions regarding the effect of partial asexuality on the distribution of genetic polymorphism has hampered comprehensive analyses and the interpretation of population genetics data.

The use of molecular markers has led to major improvements in the study of the architecture, dynamics, and evolution of clonal organisms, particularly since the development of molecular and analytical methods for detecting clonality (Halkett et al., 2005; Tibayrenc et al., 1990) and assessing clonal membership (Arnaud-Haond et al., 2007b; Tibayrenc et al., 1990). These improvements have allowed the identification of clonal replicates (i.e., ramets) of distinct "genetic individuals" (i.e., genets) in natural populations through the recognition of clonal lineages (multilocus genotypes, MLGs, or multilocus lineages, MLLs). Such identification has permitted the estimation of not only genetic (i.e., allelic richness $A$ and heterozygosity $H$ ) but also genotypic (i.e., indices based on the number of MLGs or MLLs) richness $(R)$ and diversity. Only two recent methods allow rates of clonality to be quantified from genetic data: CloNcaSe (Ali et al., 2016), developed for organisms with cyclical parthenogenesis, and ClonEstiMate (Becheler et al., 2017), a Bayesian method relying on temporal samplings ideally separated by one generation. Nevertheless, their use relies on the important but seldom met requirement of temporal sampling and rather precise knowledge of generation time.

Using single samples, most studies performed during the last two decades used the quantity of repeated genotypes as a proxy to assess the importance of clonal reproduction $(c)$ in populations. The simplest index of genotypic richness, $G$, corresponds to the number of MLGs or MLLs (Arnaud-Haond et al., 2007b). Since this specific unit of evolution (i.e., the genotype: 
Ayala, 1998) became accessible, genotypic diversity has been the subject of a growing number of studies aiming to investigate the resistance of natural populations under diverse environmental conditions (Hughes et al., 2008; Massa et al., 2013; Reusch et al., 2005). Such information is essential for understanding the evolution and dynamics of natural populations, including populations of environmental engineers (Callaghan et al., 1992; Cornelissen et al., 2014), such as corals and seagrasses, that form the basis of essential and declining coastal ecosystems (Carpenter et al., 2008; Hughes Stachowicz, 2009; Orth et al., 2006). A variety of richness and diversity metrics have thus been used to describe clonality in natural populations (Arnaud-Haond et al., 2017). Some of these indices, such as the Shannon and Simpson $\left(D^{*}\right)$ indices, were borrowed from the biodiversity literature, while others were simple richness indices $(P d=G / N$ and $R=(G-1) /(N-$ 1)) based on the ratio of the number of different genotypes $(G)$ to the sample size $(N)$ (ArnaudHaond et al., 2007b). However, the versatile and inconsistent use of these indices, combined with the lack of a common standardized sampling strategy, has prevented sound biological comparisons of the extent of clonal reproduction and its consequences for the ecology and evolution of partial asexuals (Arnaud-Haond et al., 2007a). For approximately a decade, the index of genotypic richness $R$ has been more consistently and widely used than other indices. This index is considered to reflect clonal richness in the sample only when the set of markers used is powerful enough to discriminate all distinct MLGs or MLLs (Arnaud-Haond et al., 2005). Initially thought to allow comparative studies, $R$ is also sometimes considered a proxy for the relative influence of sexual versus clonal reproduction. As such, it is expected to help clarify the consequences of reproductive strategy for the dynamics of natural populations, the nature of mutation models, the identity of the main unit targeted by natural selection and drift (genotypes or alleles), and the main drivers of migrations (propagules or adults/fragments for plants, fungi and several invertebrates, such as corals).

Unfortunately, the strong dependence of $R$ on sampling strategy and density was clearly demonstrated in two previous studies (Arnaud-Haond et al., 2007c; Gorospe et al., 2015). Those two studies, one based on a subsampling approach applied to two seagrass species and the other based on exhaustive genotyping of a coral reef, showed a complete lack of stabilization of $R$ with increasing sampling size and density. In general, the index declines as new samples are added. This unfortunate property results in the inability to derive any equivalence between the $R$ value and the extent of clonal reproduction, $c$, thus jeopardizing the management and conservation 
strategies for populations of partially asexual organisms and the ecosystems that these populations support.

Genetic diversity indices are seldom used in ecological studies to assess the influence of clonality. This may be partly because pioneering mathematical models suggest that the clonal rate has a very limited influence on the genetic composition of populations reported through departure from Hardy-Weinberg equilibrium (HWE) $\left(F_{i s}\right)$ (de Meeûs et al., 2007) and linkage disequilibrium (Navascues et al., 2010) indices. $F_{i s}$ values (heterozygote excess), when not overlooked or hastily discarded through overconservative corrections for multiple tests (Bonferroni correction, Rice, 1989), are considered indicative of high clonal rates (Halkett et al., 2005). Such an approach has been taken to interpret heterozygote excess as a signature of clonal dominance in organisms such as pea aphids (Delmotte et al., 2002; Halkett et al., 2005b) and cultivated algae (Sousa et al., 1998; Guillemin et al., 2008), while the lack of a departure from HWE, together with a high $R$, has been interpreted as indicative of predominant sexual reproduction (Krueger-Hadfield et al., 2011). More recent mathematical models have suggested the occurrence, at equilibrium, of larger interlocus variance in $F_{i s}$ values and an expected departure from HWE as the rate of clonality increases (Stoeckel Masson, 2014). Such increased variance in $F_{i s}$ is coupled with an increasingly large departure towards negative values (i.e., heterozygote excess) for extreme rates of clonality (Stoeckel et al., 2014) but also for modest rates of clonality (Reichel et al., 2016) as long as the equilibrium is not reached. These findings were more recently used to broaden the interpretation of deviations from HWE as indicative of partial (though not necessarily extreme) clonality in organisms such as invasive algae (Krueger-Hadfield et al., 2017).

Taken together, the severe sampling bias associated with $R$ and the expected influence of partial clonality on genetic parameters may explain the paradoxical observation of heterozygote excess in partially clonal organisms (Reichel et al., 2016), despite the often elevated values of $R$, which are possibly partly due to a low sampling density (Arnaud-Haond et al., 2007c; Gorospe et al., 2015). Seagrasses are a good example of this paradox. On the one hand, moderate to high levels of $R$, together with limited but significant values of genetic differentiation $\left(F_{\mathrm{st}}\right)$, at either the ramet or genet level have led some authors to propose a strong influence of sexual reproduction on the dynamics and evolution of seagrass meadows, implying the importance of recombination rates 
and large-scale dispersal (Kendrick et al., 2012; McMahon et al., 2014). On the other hand, the maximum values that $F_{\text {st }}$ can reach are strongly limited by the use of highly polymorphic molecular markers (Hedrick, 1999a, 2005; Jost, 2008). In addition, elevated values of $R$ often appear with significant but overlooked heterozygote excess, thus paradoxically suggesting a high incidence of clonality (Reichel et al., 2016; Stoeckel et al., 2019). To summarize, the most recent simulations by Stoeckel et al. (2019) clearly demonstrated a straightforward nonlinear relationship between $R$ (and, to a lesser extent, Pareto's $\beta$ diversity index; see Arnaud-Haond et al., 2007) and $c$, confirming the unreliability of $R$ in estimating $c$ when using realistic sample sizes. While genetic indices such as $F_{i s}$ and linkage disequilibrium showed a weaker relationship with $c$ unless extreme clonality occurred, $F_{i s}$ data confirmed the empirically observed (Reichel et al., 2016) tendency towards increased heterozygote excess as clonality increased, with such deviations being more pronounced before equilibrium and appearing for lower rates of clonality in smaller populations (Stoeckel et al., 2019).

To resolve this paradox and better understand the meaning of $R$ and $F$ values in relation to the extent of clonal reproduction and dispersal, we propose a reanalysis of previously published seagrass data in light of these recent modeling developments describing the effect of increasing $c$ values on the genotypic and genetic descriptors (including $R$ and $F_{\text {is }}$ ) of populations (Stoeckel et al., 2019). The four seagrasses Posidonia oceanica, Cymodocea nodosa, Zostera marina and Zostera noltii are the main species structuring coastal ecosystems along the Atlantic and Mediterranean coasts and exhibit a gradient from long-lived species exhibiting a slow turnover of shoots and low to moderate reproductive output (Posidonia oceanica and Cymodocea nodosa) to shorter-lived species (Zostera marina and Zostera noltii) that exhibit increased shoot turnover and allocation to sexual reproduction (see Box 1, the Material and Methods section and Table 1). Combining knowledge of clonal growth and the allocation patterns of the four seagrass species and more recent theoretical predictions of increasing heterozygote excess with increasing levels of clonality, we expected a progressive increase in genotypic richness along the gradient from $P$. oceanica to $Z$. noltii. We expect this trend to be coupled with a progressive decrease in heterozygosity, starting with negative $F_{i s}$ values (heterozygote excess) and moving towards null (or slightly positive when heterozygote deficiency occurs due to inbreeding) $F_{\text {is }}$ values for shorterlived species. A negative relationship is thus expected between $c$ and $R$ provided that the sampling 
strategy (and density) is similar, together with a positive relationship between $R$ and $F_{i s}$ values (Box 1).

Box 1: Main biological features of the four studied seagrasses and the associated hypothesis about clonal architecture and genetic signatures.

Studies of the growth and dynamics of the four main European seagrasses, which inhabit coastal habitats from the inter- and subtidal compartments (Z. marina and Z. noltii) to water depths reaching and occasionally greater than 50 meters ( $C$. nodosa and $P$. oceanica), have shown marked discrepancies in the shoot growth, turnover and lifespan of these species, as well as their investments in sexual reproduction.

These findings imply differences in the relative incidence of clonal reproduction in the short and long terms, affecting the pattern of spatial occupation as well as the temporal dynamics of shoots and meadows at both ecological and evolutionary time scales. These differences are summarized in the schematic below, together with a hypothesis about the expected clonal signature tested in the present work and parameters describing the genotypic richness $(R)$ and genetic composition $\left(F_{\text {is }}\right)$ of meadows. 


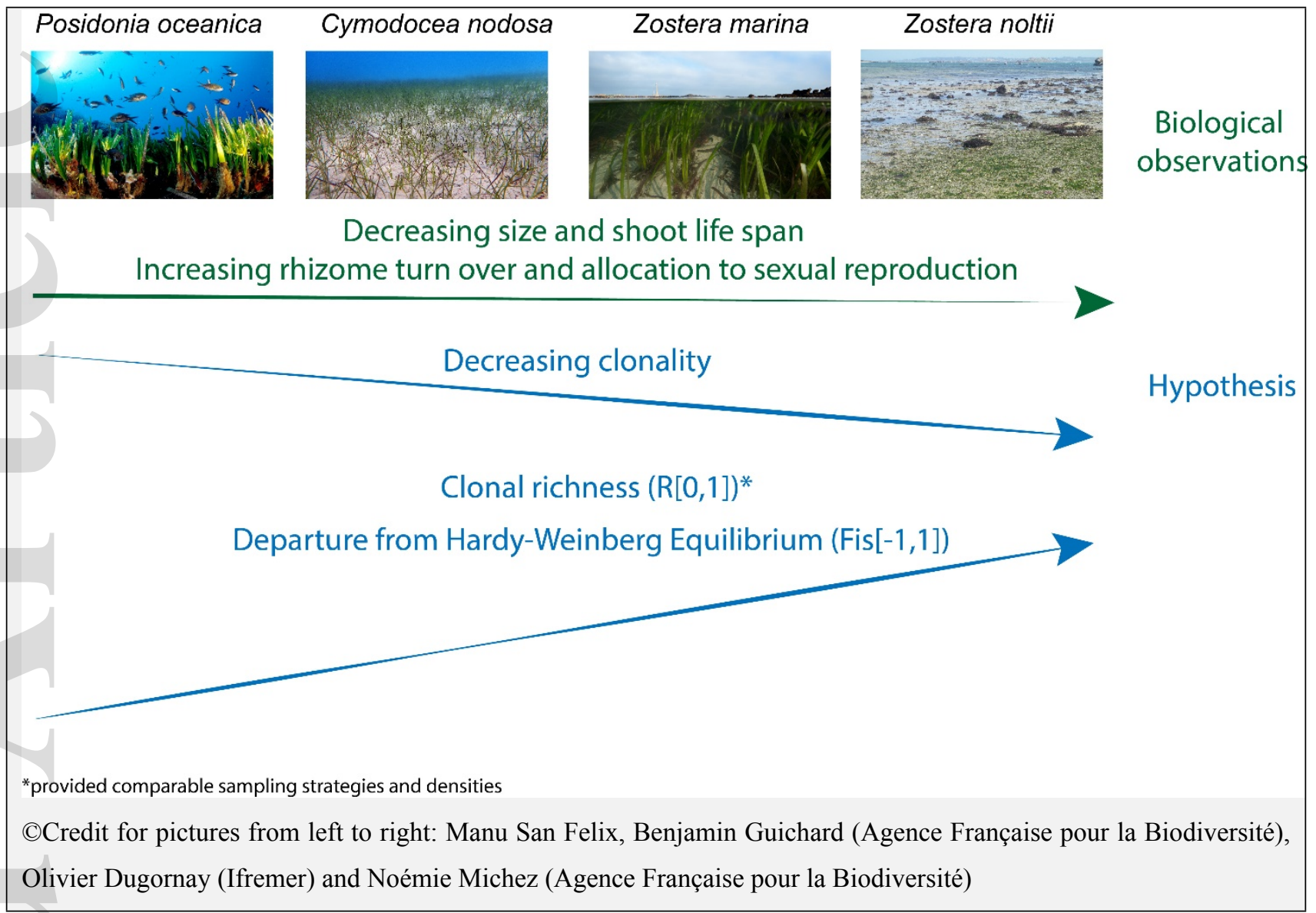

Here, we aimed to test these theoretical expectations (summarized in Box 1) by using a meta-analysis of population genetic data published on these four seagrass species to answer the following questions:

1) Do estimates of genotypic richness (R) and diversity ( $\left.D^{*}\right)$ deliver informative values that can be used to assess relative investments in clonal versus sexual reproduction among species submitted to similar sampling schemes? We hypothesized that $R$ and $\mathrm{D}^{*}$ would increase with investment in sexual reproduction, i.e., with decreases in size, shoot lifespan and rhizome turnover.

2) Does $F_{i s}$ in natural meadows reliably reflect the relative importance of clonal versus sexual reproduction among species with different investments in clonal growth and different lifespans? If so, larger departures towards negative $F_{i s}$ values, with a positive relationship between $\mathrm{R}$ and $F_{i s}$, are expected for longer-lived species with a longer shoot lifespan and greater rhizome turnover.

This article is protected by copyright. All rights reserved 
3) Do the two families of parameters (genotypic and genetic) provide congruent qualitative estimates at both the interspecific and intraspecific levels (i.e., are the same tendencies observed at both levels)?

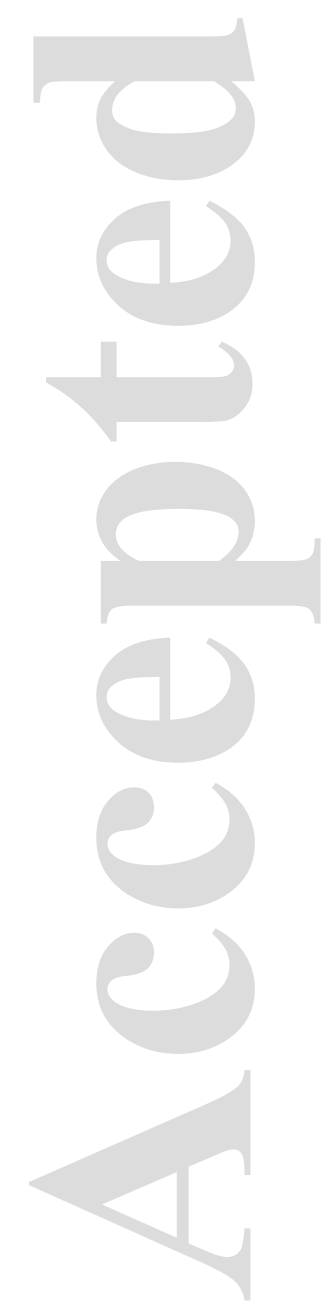

This article is protected by copyright. All rights reserved 


\section{Material and methods}

\section{Studied species}

Seagrasses reproduce clonally through rhizome elongation, and the rhythm and shape of this process differ among the studied species and largely scale with plant size (Duarte, 1991a; Marba Duarte, 1998). P. oceanica and C. nodosa are known to exhibit more stable rhizome connections, a longer shoot life span and a lower shoot turnover than other seagrass species (DiazAlmela et al., 2008; Duarte, 1991a; Marba et al., 1996; Marba et al., 1998). In contrast, Zostera species exhibit the fastest growth but a more limited occupation of space (Marba et al., 1998; Sintes et al., 2006), as well as a much shorter lifespan.

Plant size thus appears to be strongly related to turnover time and module (i.e., rhizome internode, leaf cluster and root) longevity (Duarte, 1991a). These parameters of clonal growth are accompanied by a relatively parallel trade-off between clonal architecture and sexual reproductive output. The events and success of flowering are highly temporally and spatially heterogeneous for $P$. oceanica and $C$. nodosa, which seldom produce more than several tens of seeds per square meter; in contrast, highly profuse episodes of annual flowering in Zostera can lead to the production of thousands of seeds per square meter (Marba et al., 1996; Marba et al., 2004). Finally, Zostera spp. and P. oceanica are hermaphrodites, while C. nodosa is dioecious (Larkum \& Den Hartog, 1989).

These descriptions of clonal architecture and sexual reproduction features lead to the expectation of a decreasing influence of clonality from P. oceanica to C. nodosa, Z. marina and Z. noltii (see Table 1). Although no numerical estimates of shoot lifespan and rhizome turnover are available for the smallest and shorter-lived species $Z$. noltii, it is expected to exhibit a much higher turnover rate than the other species, in line with its habitat, which is characterized by relatively unstable environmental conditions (Duarte, 1991b). The fact that $C$. nodosa is an obligate outcrosser while the other species can theoretically practice selfing may, however, result in different effects of sexual reproduction and clonality on the distribution of $F_{\text {is }}$ in this species compared to the other three and is likely to affect the gradient expected on the basis of the sole influence of clonality (Box 1).

Interestingly, these species also often exhibit a gradient on the shore (Duarte, 1991b). $P$. oceanica and $C$. nodosa reach depths of up to 40 to 50 meters (with P. oceanica dominating at greater depths, den Hartog, 1970), while the two Zostera species are most often encountered in 
intertidal areas, with Z. noltii sometimes exposed to desiccation and stressful conditions (Massa et al., 2009). All four species have been the focus of large-scale genetic surveys in phylogeographic studies performed in the past few decades. Datasets are thus available that can be used to test expectations about the investment of the species in clonal reproduction and to screen for signatures of effects of clonal reproduction on their genetic composition.

\section{Genetic datasets}

The $P$. oceanica dataset contains 36 samples of approximately 40 units each, with a total of 1424 shoots or connected shoots representing sampling units (SUs). These samples were collected from Spain to Cyprus, a range of over $4000 \mathrm{~km}$ of coastline. At each sampling site, the SUs were collected according to randomly defined coordinates in a quadrat 80 meters long and 20 meters wide. Seven microsatellite markers were used: Po15, Po5, Po5-40, Po5-49, Po5-10, Po4-3 and Po5-39. The database of genotypes was constructed in a previous meta-analysis (Arnaud-Haond et al., 2014, Arnaud-Haond et al., 2014b for the dataset). Three meadows that were initially studied for the impact of farms on the genetic composition of the species (the Amathous, Acqua Azzura and Agias Nicholaos populations; Diaz Almela et al., 2007) were discarded to avoid introducing bias.

The C. nodosa dataset (Alberto et al., 2008) consisted of 47 meadows containing approximately forty SUs each, with a total of 1586 SUs from Cyprus to the Canary Islands and Madeira. In each meadow, the SUs were selected randomly in a quadrat 60 meters long by 14 meters wide. Eight microsatellite markers were used: Cn2-38, Cn2-14, Cn2-24, Cn4-19, Cn2-16, Cn2-18, Cn4-29 and Cn2-45 (Arnaud-Haond et al., 2014; Arnaud-Haond et al., 2014b for the dataset).

The first dataset for Z. marina consisted of 13 quadrats sampled in 7 meadows with 30 SUs per quadrat, resulting in a total of 390 SUs. The meadows were on the Brittany coast from SaintMalo to Arradon. At each sampling site, SUs were randomly selected in two quadrats 20 meters long by 30 meters wide in 2009 (Becheler et al., 2013; the same sampling was performed in 2011, but in order to avoid partially duplicate information, only the first time series was included). A total of 9 microsatellite markers were used: GA35, GA2, GA17H, GA23, GA12, GA19, GA20, GA16 and GA17D (Becheler et al., 2014; Becheler et al., 2010; Becheler et al., 2013 for the dataset). The second dataset consisted of 14 meadows from Greenland to Southern Iberia, in which 427 SUs at least 1-1.5 m apart were collected haphazardly (Diekmann Serrão, 2012a) and 
genotyped with 8 microsatellite markers: GA6, GA3, CT17H, CT19, CT3, CT20, GA2 and CT35 (Diekmann Serrão, 2012b). This second dataset was not available and was thus used only for the analysis of $R$ and $F_{\text {is }}$ without replicates, as disclosed in the aforementioned article.

The Z. noltii dataset included 33 meadows sampled across the entire geographic range of the species and genotyped with 9 microsatellite markers: ZnB1, ZnH10, ZnB3, ZnB8, ZnH8, ZnD6, ZnE7, ZnF8 and ZnF11 (Coyer et al., 2004). Different sampling protocols were used and are detailed in the original publication; these protocols included the random collection of SUs within quadrats 60 meters long by 20 meters wide, 10 meters long by 15 meters wide and 10 meters long by 25 meters wide, as well as sampling along a linear transect every meter. One sampling site (BSea3) with a single SU was excluded from the initial dataset; thus, 32 meadows were kept for a total of 1117 SUs.

\section{Genetic and genotypic indices}

RClone 1.0.2 (Bailleul et al., 2016) in R statistical software (R Core Team, 2018) and GenClone (Arnaud-Haond \& Belkhir, 2007a) were used to manage the different datasets and to compute the genetic and genotypic indices of interest. We chose to examine the genetic index $F_{i s}$, for which models delivered several theoretical predictions, and the genotypic richness index $R$, often used to infer the sexual reproduction rate; $F_{i s}$ was estimated using Genetix (version 4.05; Belkhir et al., 2004). We also aimed to compare the results with the unbiased estimator of the complement of the Simpson index (estimator $L$ ) of heterogeneity, known as one of the indices least sensitive to sample size (Lande, 1996) and modified to vary positively with heterogeneity (Pielou, 1969) between 0 and approximately 1-(1/G):

$$
D^{*}=1-L=1-\sum_{i=1}^{G}\left[\frac{n_{i}\left(n_{i}-1\right)}{N(N-1)}\right]
$$

where $n_{i}$ is the number of sampled units with $M L L_{i}$.

\section{Statistical analysis and hypothesis testing}

First, to address our first question and associated theoretical expectations, the relationships of expected investment in sexual reproduction with $R$ and $D^{*}$ were computed for each population, and the distributions of values were compared among species using boxplots.

The second theoretical expectation of decreases in both $R$ and $F_{i s}$ values with an increase in clonal 
investment was first tested by computing $F_{\text {is }}$ for each population with (ramet level) and without (genet level) replicates and by comparing the distributions of this index among species using boxplots. Correlation analysis between $R$ or $D^{*}$ and $F_{i s}$ was then performed using $\mathrm{R}$ v.3.5.2 (R Core Team, 2018). A Shapiro test was performed to infer the normality of the distribution; as this null hypothesis was rejected for all indices, the Spearman correlation index between $R$ or $D^{*}$ and $F_{i s}$ was chosen, and its significance was assessed on the basis of a unilateral test with the underlying assumption of a positive relationship between $R$ and $F_{i s}$ values (so that the relationship, if detected, would be positive).

Finally, the third question about the existence of a nested pattern of relationships at the inter- and intraspecific levels was tested by performing correlation tests both between species and between meadows within species.

Distributions of values were plotted with the software GraphPad Prism version 8.4.2 for Windows (GraphPad Software, La Jolla California USA, www.graphpad.com).

\section{Results}

Genotypic richness, $R$

In line with the first theoretical expectation, the mean $R$ increased gradually from $P$. oceanica, the largest species with the longest shoot lifespan and a lower shoot turnover, to $C$. nodosa, to Z. marina and then to Z. noltii, the smallest species with the shortest lifespan and the highest shoot turnover (Table 1, Figure 1). The variance (reflected by the maximal and interquartile ranges) of these values decreased from P. oceanica to Z. noltii. Only C. nodosa slightly departed from this trend, with a mean $R$ lower than that of $P$. oceanica and the greatest maximal range of $R$ values among the seagrasses, despite a slightly shorter shoot lifespan (and expectedly higher shoot turnover) than $P$. oceanica. For $D^{*}$ (Table 1; Figure $\mathrm{S} 1$ ), the values were constrained to a narrower range, and the ranking of values among the four species was thus not as informative, although there were clearly lower values for the longer-lived species $P$. oceanica and C. nodosa than for Zostera spp.

\section{Inbreeding coefficient, $F_{\text {is }}$}

As expected from the second question and associated theoretical expectation detailed in the introduction, $F_{i s}$ values and their means progressively increased from the expectedly longest-lived 
species $P$. oceanica to the shortest-lived species Z. noltii (Table 1; Figure 1). Only Z. noltii showed a slightly positive mean $F_{i s}$. The interquartile values were nearly strictly negative for $P$. oceanica and C. nodosa, with increasingly positive $F_{i s}$ values from Z. marina to Z. noltii. This progression of $F_{i s}$ interquartile values was clearer when the datasets were analyzed without replicates (Figure 1) than when they were analyzed with replicates (Figure S1).

\section{Relationships between clonal indices and $F_{\text {is }}$}

The hypothesis of a positive relationship between $R$ and $F_{i s}$ values was further confirmed at the interspecies level: the relationships between $R$ and $F_{i s}$ were positive and significant at the ramet level $\left(r^{2}=0.41, p<0.0001\right.$; Figure 3$)$. When considering only the genets (i.e., no replicates), the results were similar, but the correlations were weaker $\left(r^{2}=0.12, p<0.0001\right.$; Figure S3). Similar relationships emerged between $D^{*}$ and $F_{i s}$ at the ramet and genet levels $\left(\mathrm{r}^{2}=0.48, \mathrm{p}<0.0001\right.$ and $\mathrm{r}^{2}=0.10, \mathrm{p}<0.001$, respectively; Figures 3 and S3). Finally, to answer the third question listed in the introduction about the extension of interspecies to intraspecies relationships, the relationships of $R$ and $D^{*}$ with $F_{i s}$ were also positive and significant at the intraspecies level (Table 1) for all but the $Z$. noltii datasets. At the ramet level (Figure 2), the relationships ranged from highly positive ( $P$. oceanica and C. nodosa) to slightly positive (Z. marina) and nearly null (Z. noltii). Comparable results, though with weaker correlations, were obtained without replicates (Figure S2, Table 1), with the exception of a lack of significance for Z. marina at the genet level. Similar results were observed for $D^{*}$ (Figure $\mathrm{S} 2 \mathrm{~b}$ ).

\section{Discussion}

Here, we conducted a comparative reanalysis of genetic data from four species. The thorough ecological knowledge of the clonal architecture of these species allowed predictions obtained from recent mathematical developments to be tested and validated. Our analyses confirmed nearly all expectations derived from recent mathematical predictions about the relationships between 1) the turnover and longevity of shoots, 2) the prevalence of clonality, and 3) the consequential genotypic signatures and, above all, genetic composition of natural meadows. When assessing the balance between clonal and sexual reproduction, by giving more weight to the genetic composition signature $\left(F_{\text {is }}\right)$ than to the genotypic indices, which are highly sensitive to 
sampling (i.e., $R$ ), this analysis unraveled an apparent paradox reported in the literature: the frequent observation of an apparently high $R$, which suggests a high rate of sexual input, and systematic departure from HWE towards heterozygote excess, which suggests a very high rate of asexual reproduction. The results were in line with recent theoretical developments (Stoeckel et al., 2019), showing a barely discernible effect of $c$ on $R$ (also very weak on $D^{*}$ ) and a much clearer effect on $F_{\text {is. }}$ This trend was clear at both the interspecies and intraspecies (among-meadow) levels, showing a nested pattern at both scales. Consequently, these results illustrate the need for a revised framework for the interpretation of molecular data from partial asexuals, such as seagrasses, which may have important consequences for conservation and management strategies in the context of global change and increasing restoration needs (Carpenter et al., 2008; Hughes et al., 2008; Orth et al., 2006).

\section{Fitting empirical data to model predictions}

Our results support the ecological hypothesis that the clonal multiplication of ramets for the growth and maintenance of populations (compared to sexual input through seedlings) increases in importance with an increasing module lifespan.

First, the mean $R$ gradually increases with decreasing longevity and increasing module turnover, i.e., from P. oceanica to Z. noltii (Figure 1), and $D^{*}$ follows a similar trend despite exhibiting a narrower range of values. Although unable to provide a reliable quantitative assessment of the rates of clonality due to large subsampling bias (Arnaud-Haond et al., 2007b; Becheler et al., 2017; Gorospe et al., 2015; Stoeckel et al., 2019), $R$ may remain useful in comparative studies and shows a broader range of discriminable scenarios than $D^{*}$. With a comparable sampling scheme and effort, $R$ (and $D^{*}$ ) can help assess the relative importance of clonality among natural populations. Such comparability was true here for $P$. oceanica and $C$. nodosa and partly for the Zostera species. It is thus important to bear in mind that the use of $R$ (and $D^{*}$ ) here was by no means an attempt to estimate $c$ but was for comparing the values obtained for meadows sampled with similar sampling scales and strategies.

In fact, the high richness of $Z$. noltii in this analysis may have been influenced by both the short lifespan (and high turnover) of its shoots and the slightly different sampling designs used to gather the data analyzed for the species. Indeed, the $Z$. noltii datasets were collected by sampling along mostly linear transects, while the datasets of the other three species were randomly or haphazardly sampled in a standardized area appropriate for their known clonal architecture, which 
should have minimized bias (Pielou, 1966) and enabled comparative analysis. Linear transects result in significantly higher genotypic diversities than other sampling methods due to a strong edge effect (Arnaud-Haond et al., 2007b). It is thus not possible to rigorously disentangle the effects of high rhizome turnover and low shoot longevity from putative edge effects on the ranking of $Z$. noltii in terms of $R$. However, the expected ranking based on $F_{\text {is }}$ stands (Figure 1), suggesting that life history traits had a stronger influence than sampling bias on these results.

This importance of sampling is reflected in a different way by the slight deviation from this general trend for C. nodosa. Despite having a slightly higher rhizome turnover than $P$. oceanica (Duarte, 1991a), C. nodosa shows lower mean $R$ (as well as lower mean $D^{*}$ ) values and a comparable distribution of $F_{i s}$ values with a tendency towards more extreme cases of heterozygote excess when all ramets are included (Figure S1). Several hypotheses can explain this result. First, despite a slightly higher rhizome turnover and a much shorter shoot lifespan in C. nodosa than in $P$. oceanica, the establishment and dynamics of $C$. nodosa meadows may rely more on clonal reproduction than those of $P$. oceanica meadows. Indeed, $C$. nodosa exhibits irregular sexual reproductive events dependent on environmental conditions but also exhibits a much faster clonal extension rate than P. oceanica (Marba et al., 1996; Marba et al., 2004). Moreover, although $C$. nodosa and $P$. oceanica were collected with an identical sampling strategy, the $C$. nodosa dataset contained more highly clonal meadows than the $P$. oceanica dataset, which may have been partly due to its obligate dioecy (leading colonizers, if alone, to rely on clonal growth), as well as the inclusion of sampling sites located at the limit of its distribution (Billingham et al., 2003). In fact, repeating the same analysis in Mediterranean populations delivered higher mean $R$ (and $D^{*}$ ) values, which were comparable only to those of $P$. oceanica, and a slightly less negative $F_{i s}$, providing a better fit to the initial predictions.

Second, the increasing departure from HWE towards negative $F_{i s}$ values (heterozygote excess, Figures 1 and 2) from $Z$. noltii to $P$. oceanica also supports the prediction of mathematical models (Stoeckel et al., 2014). As the prevalence of clonality increases, the trajectory of the population towards equilibrium slows down for both positive and negative $F_{\text {is }}$ values, with less positive than negative $F_{i s}$ values (Reichel et al., 2016). In fact, $F_{i s}$ values are usually negative for $P$. oceanica and $C$. nodosa, and an increasing proportion of positive values are observed for $Z$. marina and Z. noltii. The tendency towards heterozygote excess for the first two species is even clearer when the data are considered at the genet (without replicates, Figure 1) rather than the ramet (Figure $\mathrm{S} 1$ ) scale, with only interquartile $F_{\text {is }}$ values equal to or greater than 0 . 
Interestingly, this interspecies pattern is also observed at the nested, intraspecies level (Figure 2 and Figure $\mathrm{S} 2$ ), showing that the relationship between estimates of $R$ and $F_{\text {is }}$ transcends the species boundary and applies within species at the meadow scale. This phenomenon is reflected by a positive correlation between $F_{i s}$ and $R$ among meadows for $P$. oceanica, $C$. nodosa and Z. marina (Table 1), again supporting the predictive power of population genetics models that explicitly take partial clonality into account. Using a standard sampling strategy, many more clonal meadows (i.e., those exhibiting lower $R$ values) tend to exhibit greater departures from HWE towards heterozygote excess (negative $F_{\text {is }}$ values), again in line with theoretical predictions.

Finally, three of the four species are hermaphrodites, with no existing data suggesting selfincompatibility. Nevertheless, all of the species show heterozygote excess at the ramet level, and this excess is maintained at the genet level to a different extent for two of the species. Sexual reproduction significantly departing from random mating due to selfing or inbreeding could pull $F_{i s}$ towards positive values reflecting heterozygote deficiency, eliminating at least part of the signature of clonality. Here, if any inbreeding or selfing occurred in populations of the three hermaphroditic species, negative $F_{\text {is }}$ values would still suggest a predominant influence of clonal over sexual reproduction. The occurrence of such departure from random mating may, however, explain the fact that $C$. nodosa, which is the only obligate outcrosser, is also the species that slightly departs from the global ranking expected among species by showing extreme heterozygote excess similar to or higher than the values obtained for the longer-lived species $P$. oceanica.

Considering the accumulated ecological and physiological knowledge of the rhizome growth and dynamics of these species, our comparison of theoretical predictions derived from a "simple" Wright-Fisher-like model extended to explicitly include clonality, combined with the population genetics data gathered for four seagrass species, shows remarkable congruence. This result highlights the needs to i) extend population genetics theory to predict the dynamics of genetic diversity while accounting for various reproductive systems and ii) expand the production and interpretation of empirical data to enhance our understanding of the main drivers of demography and connectivity in natural populations, as well as the possibility of achieving these goals.

Implications for understanding clonal versus sexual prevalence and its influence on the dynamics and evolution of natural populations

Species ranges are the result of multiple ecological and evolutionary drivers, among which 
genetic drift, selection and dispersal are essential processes strongly influenced by both environmental factors and demography (Gaggiotti, 2017). The accurate use of molecular markers and population genetics tools and models to infer demographic dynamics and history from molecular data thus requires a good theoretical understanding of the ways by which evolutionary forces, including the reproductive system, drive the temporal and spatial dynamics of genetic polymorphism. New theoretical works are needed not only to explore a broader range of life history traits (including, for example, genetic architecture under the combined effects of clonality and haplo-diploidy or selfing) but also to target the development of estimators of $c$ from genetic data. In fact, current indices based on classic ecological (i.e., nonexhaustive) sampling mostly provide imperfect proxies of the relative importance of clonal versus sexual reproduction (Stoeckel et al., 2019). Understanding the respective roles of clonal and sexual recruitment and dispersal in determining local demography and spatial connectivity is essential for forecasting the evolution of these features in the context of global change and future range shifts. This knowledge is also a prerequisite for defining accurate management measures, and the effort to obtain this knowledge has been a strong incentive underlying population genetics studies of seagrass during the past few decades (Alberto et al., 2005; Arnaud-Haond et al., 2007b; Arnaud-Haond et al., 2012; Kendrick et al., 2012). Although the importance of clonal growth in the colonization, expansion, and maintenance of meadows has long been acknowledged (Duarte, 1991b; Kendrick et al., 2012), recent studies have proposed migration via the production and dispersal of seeds as a possible central driver of the dynamics and persistence of seagrasses (Kendrick et al., 2012; McMahon et al., 2014). This hypothesis is rooted in the observation of moderate to elevated levels of genotypic and genetic diversity, together with limited genetic differentiation and isolation by distance, in a panel of species that contains the four species targeted here and the Australian species Posidonia australis, the Pacific species Zostera pacifica and the Atlantic species Thalassia testudinum (Kendrick et al., 2012).

Despite being represented by a limited number of species (approximately 70), seagrasses are characterized by diverse life history traits (Hemminga Duarte, 2000; McMahon et al., 2014), as illustrated by the panel of four species examined here. The hypothesis proposed by Kendrick et al. (2012) may thus apply to some seagrass species, particularly short-lived species producing a large number of seeds (Phan et al., 2017), especially if one also accounts for the dispersal of vegetative fragments (McMahon et al., 2014). However, the prevalence of clonality is associated with a decrease in the loss of diversity due to the influence of drift (Reichel et al., 2016), which may 
partly explain the elevated levels of genetic diversity observed in well-established meadows. Such high levels of alpha diversity also intrinsically limit the maximum possible estimates of beta diversity ( $F_{\text {st }}$; Charlesworth, 1998; Gregorius, 2010; Hedrick, 1999b) and their saturation, which can be well described by the disruption of isolation-by-distance patterns over large scales (Kendrick et al., 2012).

Part of the observations that led to the hypothesis of a central role of seed dispersal may thus reflect the prevalence of clonal reproduction, regardless of whether high connectivity exists. In fact, similar observations of high diversity and limited $F_{\text {st }}$ with no large-scale pattern of isolation by distance led to the exploration of mutation patterns across the distribution range of the long-lived species $P$. oceanica and C. nodosa at the distribution range scale (Arnaud-Haond et al., 2014). Disentangling the spatial distribution pattern of polymorphism revealed that the accumulation of somatic mutations through clonal propagation had a stronger influence than the pattern of dispersal of sexual propagules, implying that the influence of clonal reproduction on the dynamics and evolution of meadows at large spatial (distribution range) and temporal (evolutionary) scales was stronger than that of sexual reproduction (Arnaud-Haond et al., 2014).

The results presented here thus support the coexistence of complex trade-offs between clonal and sexual reproduction and dispersal among seagrass species, which may be better understood by specifically taking into account the wide diversity of life history traits that these species express (McMahon et al., 2014). Disentangling these cases individually and accurately assessing the level of genotypic diversity, as well as the influence of genotypic diversity on the resistance of natural populations (Hughes et al., 2008; Massa et al., 2013; Reusch et al., 2005), are challenging but also extremely important for designing sound management and restoration strategies in a fluctuating environment (McMahon et al., 2017), representing a major research axis to develop in the future. Marine connectivity research has been enriched in recent years by the improvement of predictive (oceanographic modeling, Robert Sponaugle, 2009) and molecular (next-generation sequencing and high-density genome scan) (Riginos et al., 2016; Selkoe et al., 2016) tools. The former can be readily enriched through the extensive knowledge gained by seagrass ecologists on the broad diversity of life history traits determining the timing and extent of the production and dispersal of sexual and clonal propagules (Duarte, 1991a; McMahon et al., 2014). The latter will certainly facilitate research on seagrass population genetics by allowing a finer-grained snapshot of the distribution of polymorphisms and the various origins of mutations at nested spatial scales to better disentangle the relative impacts of different evolutionary forces on 
their emergence and spatial spread. Finally, the integration of oceanographic and molecular information in new integrative Bayesian analysis frameworks is currently underway (Gaggiotti, 2017) and represents a promising path for uncovering the diversity and complexity of seagrass strategies in terms of demography and dispersal.

\section{Conclusion}

The data reanalyzed here for four seagrass species support both i) the ecological hypothesis of higher clonality in longer-lived, lower-turnover species and ii) the mathematical hypothesis of greater deviation from HWE towards an excess of heterozygotes at higher levels of clonality. This reanalysis also supports iii) the statistical prediction that, with the usual sampling density and grain size (although useful in comparative studies with rigorously standardized sampling strategies), the use of $R$ to infer $c$ will systematically lead to gross underestimates of the true prevalence of clonality (Arnaud-Haond et al., 2007b; Gorospe et al., 2015; Stoeckel et al., 2019). The results, which were obtained for three hermaphroditic species and an obligate outcrosser, also suggest that the screening of $F_{i s}$ would greatly aid in assessing the importance of clonal reproduction for many species, including self-fertilizing species, depending on the importance of clonal reproduction and selfing. These results, in line with theoretical predictions, thus support the use of the signature of heterozygote excess (a negative $F_{\text {is }}$ ), which is less prone to large sampling bias than $R$, to assess the extent of clonal versus sexual reproduction. However, nonnegative $F_{\text {is }}$ values may not be interpreted as the absence of partial clonality, particularly in cases where other forces (species exhibiting the potential for high selfing rates or datasets prone to null alleles, for example) may counterbalance the effect of clonality on $F_{\text {is }}$. By emphasizing this often-overlooked signature of clonal prevalence in the literature, the results also call for a revision of our perception of the balance between sexual and clonal reproduction in natural populations of partial asexuals, such as seagrass meadows. Recent empirical and theoretical developments now provide paths towards improved estimates of these essential parameters, which will provide sound interpretations of population genetic data, elucidate the short-term drivers of the natural dynamics and resistance of meadows, forecast meadow resilience or distribution range shifts under global change, and define sound conservation strategies. Finally, this meta-analysis is the first attempt to revisit empirical data in light of recent theoretical developments (Stoeckel et al., 2019), calling for similar research on important clonal species, such as other ecosystem engineers, important crops, invasive species and pathogens. 


\section{Data accessibility}

The dataset composed of genotypic and genetic indices is available from Zenodo, together with the R Markdown scripts for statistical analysis (10.5281/zenodo.3525856). The raw genotypic data for Z. noltii are also available under the same Zenodo doi. These data were already available from Dryad for the other three species: for Posidonia oceanica and Cymodocea nodosa (Arnaud-Haond et al., 2014), https://doi.org/10.5061/dryad.3b8k6 and for Zostera marina (Becheler et al., 2010), https://doi.org/10.5061/dryad.1vp70.

\section{Acknowledgments}

We wish to thank the consortium of the ANR Clonix projects funded by the French National Research Agency (projects CLONIX: ANR-11-BSV7-007 and Clonix2D ANR-18-CE32-0001) for very useful discussions and Jim Coyer for providing the Z. noltii dataset. We also wish to thank Olivier Hardy for recommending this work in Peer Community In, as well as Stacy A. Krueger-Hadfield, Ludwig Triest and an anonymous referee, as well as Myriam Heuertz for their constructive comments on a former version of this manuscript that was peer-reviewed and recommended by the Peer Community In Evolutionary Biology (https://doi.org/10.24072/pci.evolbiol.100083).

\section{Author contributions}

SAH and SS conceived the study, and SAH and DB wrote the manuscript. SAH and DB compiled the data and performed the meta-analysis, data exploration and interpretation. All authors contributed to editing. SAH and SS were responsible for securing funding. All authors have read and approved the final manuscript.

\section{Conflict of interest disclosure}

The authors of this preprint declare that they have no financial conflicts of interest associated with the content of this article.

\section{References}


Aitken, S. N., Yeaman, S., Holliday, J. A., Wang, T., \& Curtis-McLane, S. (2008). Adaptation, migration or extirpation: climate change outcomes for tree populations. Evolutionary Applications, 1(1), 95-111. doi:doi:10.1111/j.1752-4571.2007.00013.x

Alberto, F., Gouveia, L., Arnaud-Haond, S., Perez-Llorens, J. L., Duarte, C. M., \& Serrao, E. A. (2005). Within-population spatial genetic structure, neighbourhood size and clonal subrange in the seagrass Cymodocea nodosa. Molecular Ecology, 14(9), 2669-2681. doi:10.1111/j.1365-294X.2005.02640.x

Alberto, F., Massa, S., Diaz-Almela, E., Arnaud-Haond, S., Duarte, C. M., \& Serrão, E. A. (2008). Genetic differentiation in the seagrass Cymodocea nodosa across the MediterraneanAtlantic transition region. Journal of Biogeography, 35, 1279-1294.

Ali, S., Soubeyrand, S., Gladieux, P., Giraud, T., Leconte, M., Gautier, A., . . Enjalbert, J. (2016). CloNcaSe: Estimation of sex frequency and effective population size by clonemate resampling in partially clonal organisms. Molecular Ecology Resources, 16(4), 845-861. doi:10.1111/1755-0998.12511

Arnaud-Haond, S., \& Belkhir, K. (2007a). GENCLONE: a computer program to analyse genotypic data, test for clonality and describe spatial clonal organization. Molecular Ecology Notes, 7(1), 15-17.

Arnaud-Haond, S., Duarte, C. M., Alberto, F., \& Serrão, E. A. (2007b). Standardizing methods to address clonality in population studies. Molecular Ecology, 16(24), 5115-5139.

Arnaud-Haond, S., Duarte, C. M., Diaz-Almela, E., Marbà, N., Sintes, T., \& Serrão, E. A. (2012). Implications of Extreme Life Span in Clonal Organisms: Millenary Clones in Meadows of the Threatened Seagrass Posidonia oceanica. PLoS ONE, 7(2), e30454. doi:10.1371/journal.pone.0030454

Arnaud-Haond, S., Migliaccio, M., Diaz-Almela, E., Teixeira, S. J. L., Van De Vliet, M. S., Alberto, F., . . Serrão, E. A. (2007c). Vicariance patterns in the Mediterranean Sea: eastwest cleavage and low dispersal in the endemic seagrass Posidonia oceanica. Journal of Biogeography, 34(6), 963-976.

Arnaud-Haond, S., Moalic, Y., Hernández-García, E., Eguiluz, V. M., Alberto, F., Serrão, E. A., \& Duarte, C. M. (2014). Disentangling the Influence of Mutation and Migration in Clonal Seagrasses Using the Genetic Diversity Spectrum for Microsatellites. Journal of Heredity, 105(4), 532-541. doi:10.1093/jhered/esu015.

Arnaud-Haond, S., Moalic, Y., Hernández-García, E., Eguiluz, V. M., Alberto, F., Serrão, E. A., \& 
Duarte, C. M. (2014b). Data from: Scaling of processes shaping the clonal dynamics and genetic mosaic of seagrasses through temporal genetic monitoring. Retrieved from: https://doi.org/10.5061/dryad.3b8k6

Ayala, F. J. (1998). Is sex better? Parasites say "no". Proceedings of the National Academy of Sciences of the United States of America, 95(7), 3346-3348.

Bailleul, D., Stoeckel, S., \& Arnaud-Haond, S. (2016). RClone: a package to identify MultiLocus Clonal Lineages and handle clonal data sets in r. Methods in Ecology and Evolution, 7(8), 966-970. doi:10.1111/2041-210X.12550

Becheler, R., Benkara, E., Moalic, Y., Hily, C., \& Arnaud-Haond, S. (2013). Data from: Scaling of processes shaping the clonal dynamics and genetic mosaic of seagrasses through temporal genetic monitoring. Retrieved from: https://doi.org/10.5061/dryad.1vp70

Becheler, R., Benkara, E., Moalic, Y., Hily, C., \& Arnaud-Haond, S. (2014). Scaling of processes shaping the clonal dynamics and genetic mosaic of seagrasses through temporal genetic monitoring. Heredity, 112(2), 114-121. doi:10.1038/hdy.2013.82

Becheler, R., Diekmann, O., Hily, C., Moalic, Y., \& Arnaud-Haond, S. (2010). The concept of population in clonal organisms: mosaics of temporally colonized patches are forming highly diverse meadows of Zostera marina in Brittany. Molecular Ecology, 19(12), 23942407.

Becheler, R., Masson, J.-P., Arnaud-Haond, S., Halkett, F., Mariette, S., Guillemin, M.-L., . . . Stoeckel, S. (2017). ClonEstiMate, a Bayesian method for quantifying rates of clonality of populations genotyped at two-time steps. Molecular Ecology Resources, 17(6), e251-e267. doi:10.1111/1755-0998.12698.

Belkhir K., Borsa P., Chikhi L., Raufaste N. \& Bonhomme F. 1996-2004 GENETIX 4.05, logiciel sous Windows TM pour la génétique des populations. Laboratoire Génome, Populations, Interactions, CNRS UMR 5000, Université de Montpellier II, Montpellier (France).

Billingham, M. R., Reusch, T. B. H., Alberto, F., \& Serrão, E. A. (2003). Is asexual reproduction more important at geographical limits? A genetic study of the seagrass Zostera marina in the Ria Formosa, Portugal. Marine Ecology Progress Series, 265, 77-83. doi: $10.3354 /$ meps 265077

Callaghan, T. V., Carlsson, B. Å., Jónsdóttir, I. S., Svensson, B. M., \& Jonasson, S. (1992). Clonal Plants and Environmental Change: Introduction to the Proceedings and Summary. Oikos, 
63(3), 341-347. doi:10.2307/3544959

Carlsson, B. Å., \& Callaghan, T. V. (1994). Impact of climate change factors on the clonal sedge Carex bigelown: implications for population growth and vegetative spread. Ecography, 17(4), 321-330. doi:doi:10.1111/j.1600-0587.1994.tb00109.x

Carpenter, K. E., Abrar, M., Aeby, G., Aronson, R. B., Banks, S., Bruckner, A., . . Wood, E. (2008). One-Third of Reef-Building Corals Face Elevated Extinction Risk from Climate Change and Local Impacts. Science, 321(5888), 560-563. doi:10.1126/science.1159196

Charlesworth, B. (1998). Measures of divergence between populations and the effect of forces that reduce variability. Molecular Biology and Evolution, 15(5), 538-543. doi:10.1093/oxfordjournals.molbev.a025953

Cornelissen, J. H. C., Song, Y.-B., Yu, F.-H., \& Dong, M. (2014). Plant traits and ecosystem effects of clonality: a new research agenda. Annals of botany, 114(2), 369-376. doi:10.1093/aob/mcu113

Coyer, J. A., Diekmann, O. E., Serrão, E., Procaccini, G., Milchakova, N., Pearson, G. A., . . Olsen, J. L. (2004). Population genetics of dwarf eelgrass Zostera noltii throughout its biogeographic range. Marine Ecology Progress Series, 281, 12.

de Meeûs, T., Prugnolle, F., \& Agnew, P. (2007). Asexual reproduction: Genetics and evolutionary aspects. Cellular and Molecular Life Sciences, 64(11), 1355-1372. doi:10.1007/s00018-007-6515-2

den Hartog, C. (1970). The seagrasses of the world. Internationale Revue der gesamten Hydrobiologie und Hydrographie, 56(1), 275. doi:10.1002/iroh.19710560139

Diaz-Almela, E., Marbà , N., Alvarez, E., Santiago, R., Martinez, R., \& Duarte, C. M. (2008). Patch dynamics of the Mediterranean seagrass Posidonia oceanica: Implications for recolonisation process. Aquatic Botany, 89(4), 397-403.

Diekmann, O. E., \& Serrão, E. A. (2012a). Data from: Range-edge genetic diversity: locally poor extant southern patches maintain a regionally diverse hotspot in the seagrass Zostera marina. Retrieved from: https://doi.org/10.5061/dryad.2589rn16

Diekmann, O. E., \& Serrão, E. A. (2012b). Range-edge genetic diversity: locally poor extant southern patches maintain a regionally diverse hotspot in the seagrass Zostera marina. Molecular Ecology, 21(7), 1647-1657. doi:10.1111/j.1365-294X.2012.05500.x

Duarte, C. M. (1991a). Allometric scaling of seagrass form and productivity. Marine ecology progress series. Oldendorf, 77(2), 289-300.

This article is protected by copyright. All rights reserved 
Duarte, C. M. (1991b). Seagrass depth limits. Aquatic Botany, 40(4), 363-377. doi:https://doi.org/10.1016/0304-3770(91)90081-F

Gaggiotti, O. E. (2017). Metapopulations of Marine Species with Larval Dispersal: A Counterpoint to Ilkka's Glanville Fritillary Metapopulations (Vol. 54): SPIE.

Gorospe, K. D., Donahue, M. J., \& Karl, S. A. (2015). The importance of sampling design: spatial patterns and clonality in estimating the genetic diversity of coral reefs. Marine Biology, 162(5), 917-928. doi:10.1007/s00227-015-2634-8

Gregorius, H. R. (2010). Linking Diversity and Differentiation. Diversity, 2(3), 370.

Halkett, F., Simon, J.-C., \& Balloux, F. (2005). Tackling the population genetics of clonal and partially clonal organisms. Trends in Ecology \& Evolution, 20(4), 194-201.

Hedrick, P. W. (1999a). Perspective: Highly Variable Loci and their Interpretation in Evolution and Conservation. Evolution, 53, 313-318.

Hedrick, P. W. (2005). A standardized genetic differentiation measure. Evolution, 59(8), 16331638. doi:Doi 10.1554/05-076.1

Hedrick, W. (1999b). Perspective: highly variable loci and their interpretation in evolution and conservation. Evolution, 53(2), 313-318. doi:10.1111/j.1558-5646.1999.tb03767.x

Hemminga, M. A., \& Duarte, C. M. (2000). Seagrass ecology. Cambridge University Press, Cambridge. http://dx.doi.org/10.1017/CBO9780511525551

Hughes, A. R., Inouye, B. D., Johnson, M. T. J., Underwood, N., \& Vellend, M. (2008). Ecological consequences of genetic diversity. Ecology Letters, 11(6), 609-623. doi:doi:10.1111/j.1461-0248.2008.01179.x

Hughes, A. R., \& Stachowicz, J. J. (2009). Ecological impacts of genotypic diversity in the clonal seagrass Zostera marina. Ecology, 90(5), 1412-1419. doi:10.1890/07-2030.1

Jost, L. (2008). G(ST) and its relatives do not measure differentiation. Molecular Ecology, 17(18), 4015-4026. doi:10.1111/j.1365-294X.2008.03887.x

Kendrick, G. A., Waycott, M., Carruthers, T. J. B., Cambridge, M. L., Hovey, R., Krauss, S. L., . . Verduin, J. J. (2012). The Central Role of Dispersal in the Maintenance and Persistence of Seagrass Populations. BioScience, 62(1), 56-65. doi:10.1525/bio.2012.62.1.10

Lande, R. (1996). Statistics and partitioning of species diversity, and similarity among multiple communities. Oikos, 76(1), 5-13. doi:Doi 10.2307/3545743

Marba, N., Cebrian, J., Enríquez, S., \& Duarte, C. (1996). Growth patterns of Western Mediterranean seagrasses: species-specific responses to seasonal forcing (Vol. 133). 
Marba, N., Duarte, C., Alexandre, A., \& Cabaço, S. (2004). How do seagrasses grow and spread? In (pp. 11-18).

Marba, N., \& Duarte, C. M. (1998). Rhizome elongation and seagrass clonal growth. Marine Ecology Progress Series, 174, 12.

Massa, S. I., Arnaud-Haond, S., Pearson, G. A., \& Serrão, E. A. (2009). Temperature tolerance and survival of intertidal populations of the seagrass Zostera noltii (Hornemann) in Southern Europe (Ria Formosa, Portugal). 619(1), 195-201. doi:10.1007/s10750-0089609-4

Massa, S. I., Paulino, C. M., Serrao, E. A., Duarte, C. M., \& Arnaud-Haond, S. (2013). Entangled effects of allelic and clonal (genotypic) richness in the resistance and resilience of experimental populations of the seagrass Zostera noltii to diatom invasion. BMC Ecol, 13, 39. doi:10.1186/1472-6785-13-39

McMahon, K., van Dijk, K.-j., Ruiz-Montoya, L., Kendrick, G. A., Krauss, S. L., Waycott, M., . . Duarte, C. M. (2014). The movement ecology of seagrasses. Proceedings of the Royal Society B: Biological Sciences, 281(1795), 20140878. doi:doi:10.1098/rspb.2014.0878

McMahon, K. M., Evans, R. D., van Dijk, K.-j., Hernawan, U., Kendrick, G. A., Lavery, P. S., . . Waycott, M. (2017). Disturbance Is an Important Driver of Clonal Richness in Tropical Seagrasses. Frontiers in Plant Science, 8(2026). doi:10.3389/fpls.2017.02026

Navascues, M., Stoeckel, S., \& Mariette, S. (2010). Genetic diversity and fitness in small populations of partially asexual, self-incompatible plants. Heredity, 104(5), 482-492.

Orth, R. J., Carruthers, T. J. B., Dennison, W. C., Duarte, C. M., Fourqurean, J. W., Heck, K. L., . . Williams, S. L. (2006). A Global Crisis for Seagrass Ecosystems. BioScience, 56(12), 987-996. doi:10.1641/0006-3568(2006)56[987:AGCFSE]2.0.CO;2

Pecuchet, L., Reygondeau, G., Cheung, W. W. L., Licandro, P., van Denderen, P. D., Payne, M. R., \& Lindegren, M. (2018). Spatial distribution of life-history traits and their response to environmental gradients across multiple marine taxa. Ecosphere, 9(10), e02460. doi:doi:10.1002/ecs2.2460

Phan, T. T. H., De Raeymaeker, M., Luong, Q. D., \& Triest, L. (2017). Clonal and genetic diversity of the threatened seagrass Halophila beccarii in a tropical lagoon: Resilience through short distance dispersal. Aquatic Botany, 142, 96-104. doi:https://doi.org/10.1016/j.aquabot.2017.07.006

Pielou, E. C. (1966). The measurement of diversity in different types of biological collections. 
Journal of Theoretical Biology, 13(Supplement C), 131-144. doi:https://doi.org/10.1016/0022-5193(66)90013-0

Pielou, E. C. (1969). An introduction to mathematical ecology. New-York: Wiley-Interscience.

Polidoro, B. A., Carpenter, K. E., Collins, L., Duke, N. C., Ellison, A. M., Ellison, J. C., . . Yong, J. W. H. (2010). The Loss of Species: Mangrove Extinction Risk and Geographic Areas of Global Concern. PLoS ONE, 5(4), e10095. doi:10.1371/journal.pone.0010095

R Core Team. (2018). R: A language and environment for statistical computing R Foundation for Statistical Computing, Vienna, Austria. Retrieved from http://www.R-project.org/

Reichel, K., Masson, J.-P., Malrieu, F., Arnaud-Haond, S., \& Stoeckel, S. (2016). Rare sex or out of reach equilibrium? The dynamics of F(IS) in partially clonal organisms. BMC Genetics, 17, 76. doi:10.1186/s12863-016-0388-Z

Reusch, T. B. H., Ehlers, A., Hämmerli, A., \& Worm, B. (2005). Ecosystem recovery after climatic extremes enhanced by genotypic diversity. Proceedings of the National Academy of Sciences of the United States of America, 102(8), 2826. doi:10.1073/pnas.0500008102

Rice, W. (1989). Analyzing tables of statistical tests. Evolution, 43, 223-225.

Riginos, C., Crandall, E. D., Liggins, L., Bongaerts, P., \& Treml, E. A. (2016). Navigating the currents of seascape genomics: how spatial analyses can augment population genomic studies. Current zoology, 62(6), 581-601. doi:10.1093/cz/zow067

Robert, K. C., \& Sponaugle, S. (2009). Larval Dispersal and Marine Population Connectivity. Annual Review of Marine Science, 1(1), 443-466. doi:10.1146/annurev.marine.010908.163757

Selkoe, K., D’Aloia, C., Crandall, E., Iacchei, M., Liggins, L., Puritz, J., . . Toonen, R. (2016). A decade of seascape genetics: contributions to basic and applied marine connectivity. Marine Ecology Progress Series, 554, 1-19. doi:10.3354/meps11792

Sintes, T., Marbà, N., \& Duarte, C. (2006). Modeling nonlinear seagrass clonal growth: Assessing the efficiency of space occupation across the seagrass flora. Estuaries and Coasts, 29(1), 72-80. doi:10.1007/BF02784700

Stoeckel, S., Grange, J., Manjarres, J.F., Bilger, I.,Frascaria-Lacoste, N., Mariette, S. (2006). Heterozygote excess in a self - incompatible and partially clonal forest tree species Prunus avium L. Molecular Ecology, 15(8), 2109-18. doi: 10.1111/j.1365294X.2006.02926.X

Stoeckel, S., \& Masson, J.-P. (2014). The Exact Distributions of Fis under Partial Asexuality in 
Small Finite Populations with Mutation. PLoS ONE, 9(1), e85228.

Stoeckel, S., Porro, B., \& Arnaud-Haond, S. (2019). Revising upward our appraisal of clonal rates in partially clonal organisms: the discernible and the hidden effects of clonality on the genotypic and genetic states of populations. ArXiv:1902.09365 [q-Bio] v4 peer-reviewed and recommended by Peer Community in Evolutionary Biology. Retrieved from http://arxiv.org/abs/1902.09365v4. doi: arXiv:1902.09365

Tibayrenc, M., Kjellberg, F., \& Ayala, F. J. (1990). A clonal theory of parasitic protozoa: the population structures of Entamoeba, Giardia, Leishmania, Naegleria, Plasmodium, Trichomonas, and Trypanosoma and their medical and taxonomical consequences. Proceedings of the National Academy of Sciences, 87(7), 2414-2418.

Waycott, M., Duarte, C. M., Carruthers, T. J. B., Orth, R. J., Dennison, W. C., Olyarnik, S., . . Williams, S. L. (2009). Accelerating loss of seagrasses across the globe threatens coastal ecosystems. Proceedings of the National Academy of Sciences, 106(30), 12377-12381. doi:10.1073/pnas.0905620106

Yu, F.-H., Roiloa, S. R., \& Alpert, P. (2016). Editorial: Global Change, Clonal Growth, and Biological Invasions by Plants. Frontiers in Plant Science, 7, 1467-1467. doi:10.3389/fpls.2016.01467 


\section{Figures}

Figure 1: Boxplot showing the average departure from Hardy-Weinberg equilibrium $\left(F_{\text {is, }}\right.$, without replicates; see Figure S1 for the same results at the ramet level) and genotypic richness $(R)$ values over all studied meadows for each of the four seagrass species: Posidonia oceanica, Cymodocea nodosa, Zostera marina and Zostera noltii

Figure 2: Relationships between the level of genotypic richness $(R)$ and departure from HardyWeinberg equilibrium ( $F_{\text {is, }}$ at the ramet level, i.e., with replicates; see Figure S2 for the results at the genet level) at the meadow scale for each of the four seagrass species

Figure 3: Overall relationships between genotypic richness $(R)$, the Simpson index of heterogeneity $\left(D^{*}\right)$ and departure from Hardy-Weinberg equilibrium $\left(F_{\text {is }}\right.$, at the ramet level, i.e., with replicates; see Figure S3 for the results at the genet level) at the meadow scale for each of the four seagrass species 


\section{Table 1}

Summary of the clonal growth features (Duarte, 1991) for each of the four seagrass species, the average compiled values of genotypic heterogeneity $\left(D^{*}\right)$ and richness $(R)$ and departure from Hardy-Weinberg equilibrium $\left(F_{\text {is }}\right)$ and the Spearman correlations between the two genotypic indices and the genetic index $\left(\mathrm{r}^{2} ; *: \mathrm{p}<0.05 ; * *: \mathrm{p}<0.01 ; * * *<0.001\right)$, which were obtained from the dataset including all genotyped ramets (with replicates, $F_{\text {is AR }}$ ) and the dataset including only genets (without replicates, $F_{\text {is OG }}$ ).

\begin{tabular}{|c|c|c|c|c|c|c|c|c|c|c|}
\hline & \multirow[b]{2}{*}{$\begin{array}{l}\text { rhizome } \\
\text { turnover }\end{array}$} & \multirow[b]{2}{*}{$\begin{array}{l}\text { shoot } \\
\text { lifespan }\end{array}$} & \multirow[b]{2}{*}{$R$} & \multirow[b]{2}{*}{$D^{*}$} & \multicolumn{2}{|c|}{$\begin{array}{l}\text { with replicates } \\
\text { (ramet level) }\end{array}$} & & \multicolumn{2}{|c|}{$\begin{array}{l}\text { without } \\
\text { replicates (genet } \\
\text { level) }\end{array}$} & \multirow[b]{2}{*}{$\begin{array}{l}\text { correlatior } \\
D^{* \sim} F_{\text {is OG }}\end{array}$} \\
\hline & & & & & $F_{\text {is AR }}$ & $\begin{array}{l}\text { correlation } \\
R^{\sim} F_{\text {is } \mathrm{Ar}}\end{array}$ & $\begin{array}{l}\text { correlation } \\
D^{* \sim} F_{\text {is AR }}\end{array}$ & $F_{\text {is } \mathrm{OG}}$ & $\begin{array}{l}\text { correlatio } \\
\mathrm{n} R^{\sim} F_{\text {is }} \mathrm{OG}\end{array}$ & \\
\hline $\begin{array}{l}\text { Posidonia } \\
\text { oceanica }\end{array}$ & 0.09 & 11.98 & 0.57 & 0.88 & -0.19 & $0.31 * * *$ & $0.41 * * *$ & -0.09 & $0.11^{*}$ & $0.16^{* *}$ \\
\hline $\begin{array}{l}\text { Cymodocea } \\
\text { nodosa }\end{array}$ & 0.14 & 2.4 & 0.46 & 0.77 & -0.24 & $0.64 * * *$ & $0.68 * * *$ & -0.03 & $0.13^{* *}$ & $0.12 *$ \\
\hline $\begin{array}{l}\text { Zostera } \\
\text { marina } \\
\text { Zostera }\end{array}$ & 2.19 & 1.52 & 0.64 & 0.96 & -0.08 & $0.29 *$ & $0.28 *$ & -0.04 & $0.16^{*}$ & 0 \\
\hline noltii & & & 0.75 & 0.93 & 0.02 & 0.05 & 0.04 & 0.02 & 0.05 & 0.02 \\
\hline
\end{tabular}

This article is protected by copyright. All rights reserved 


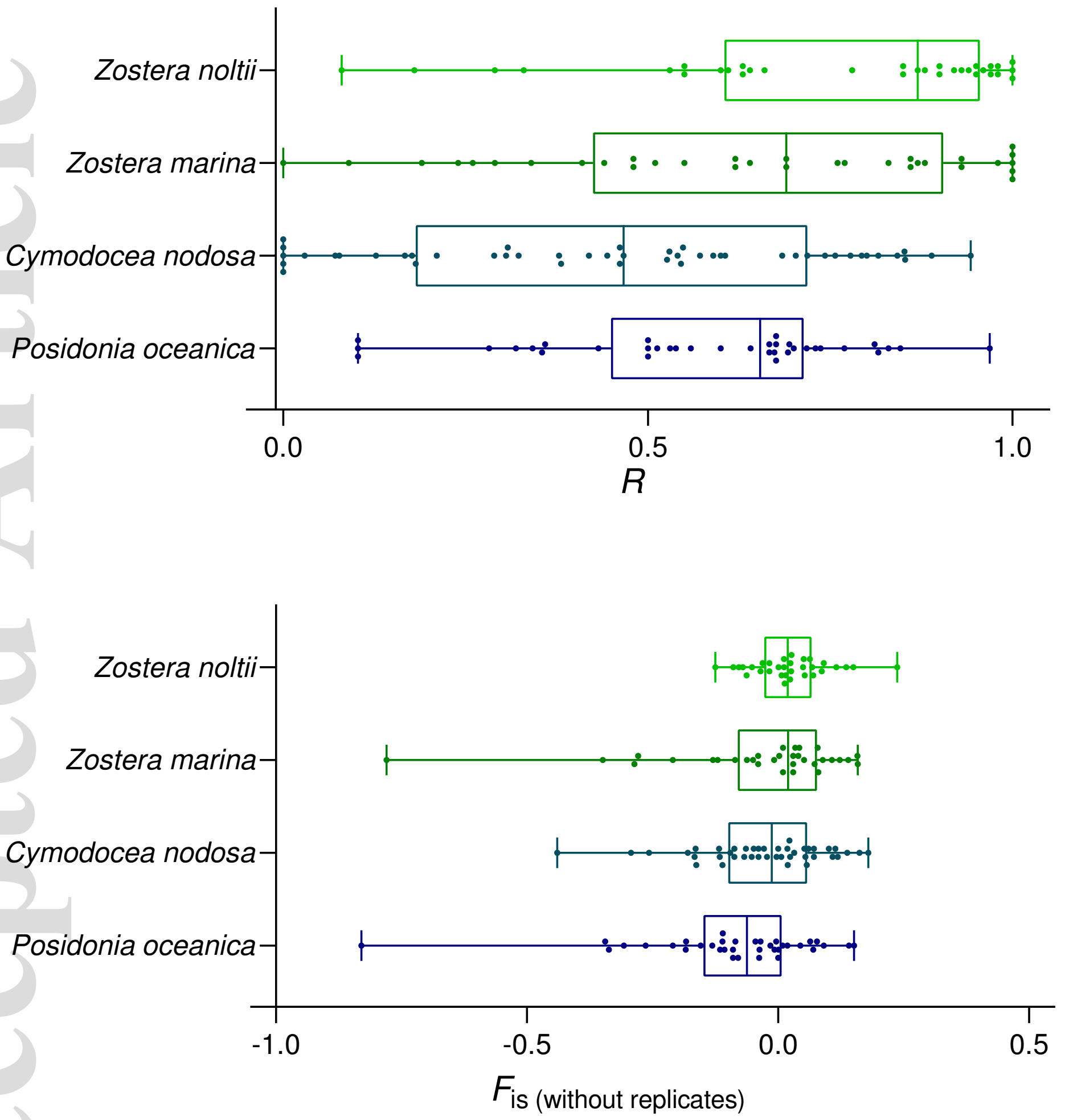

mec_15532_f1.eps

This article is protected by copyright. All rights reserved 

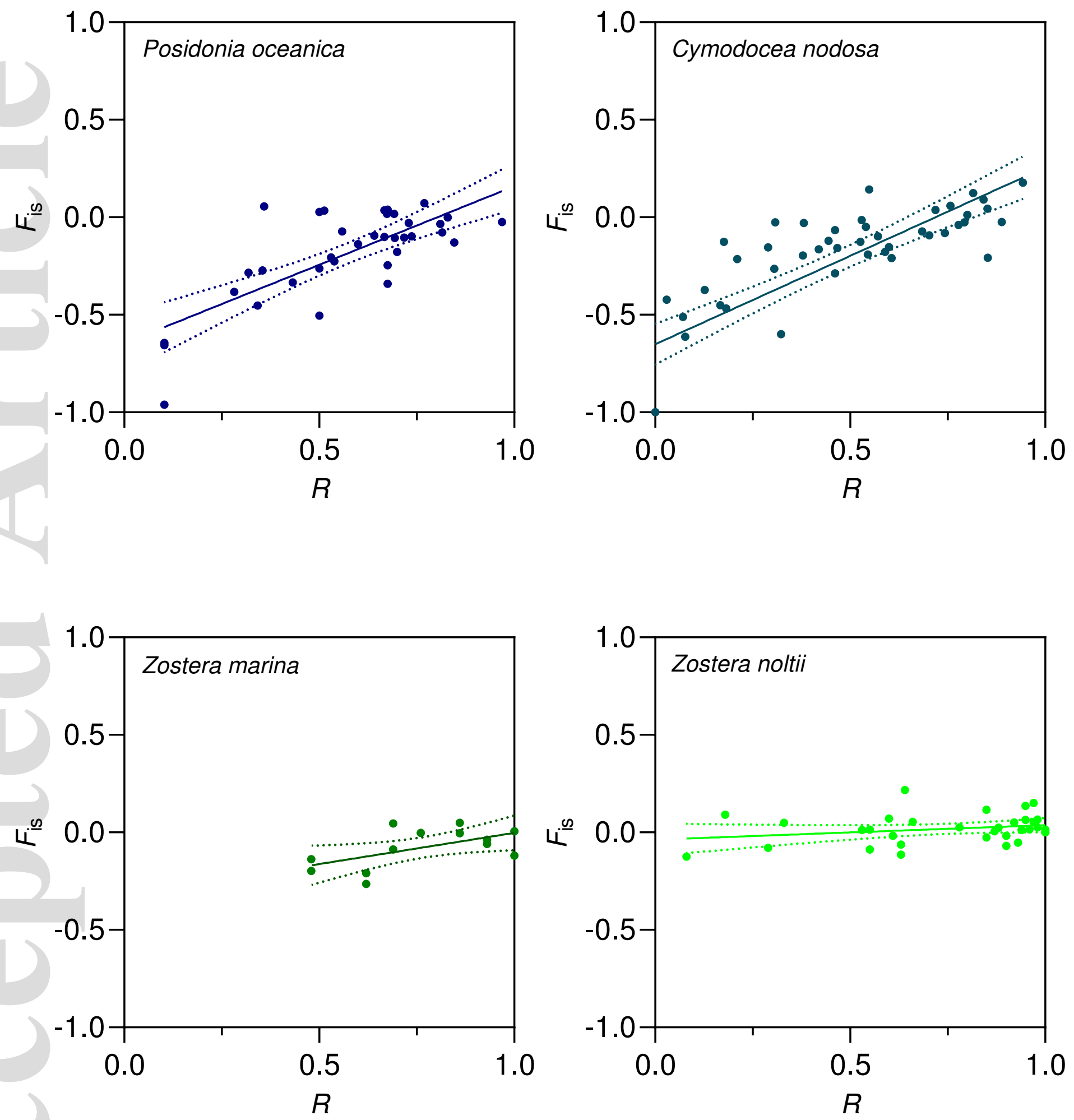

This article is protected by copyright. All rights reserved 


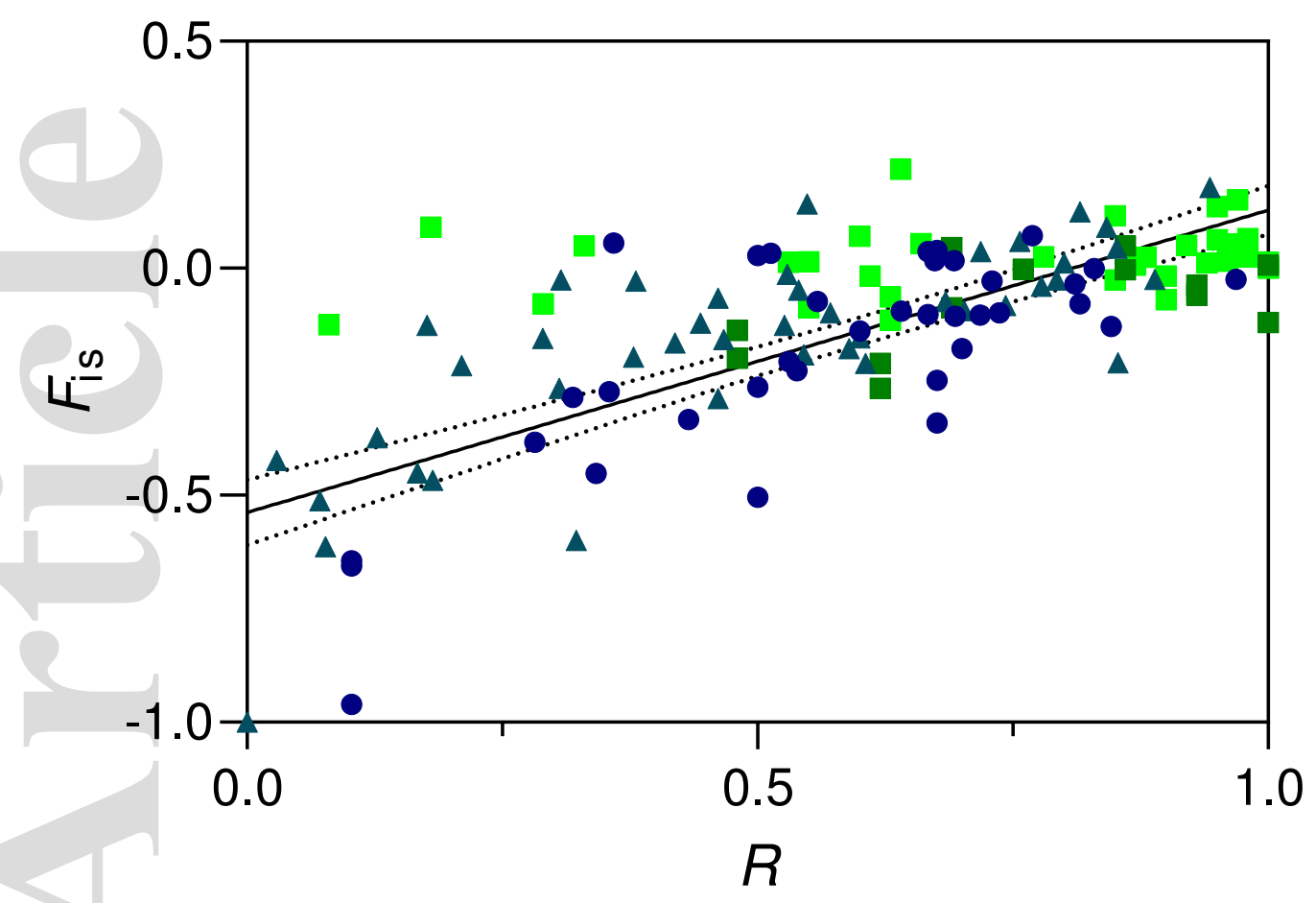
- Overall
- Posidonia oceanica
- Cymodocea nodosa
- Zostera marina
- Zostera noltii

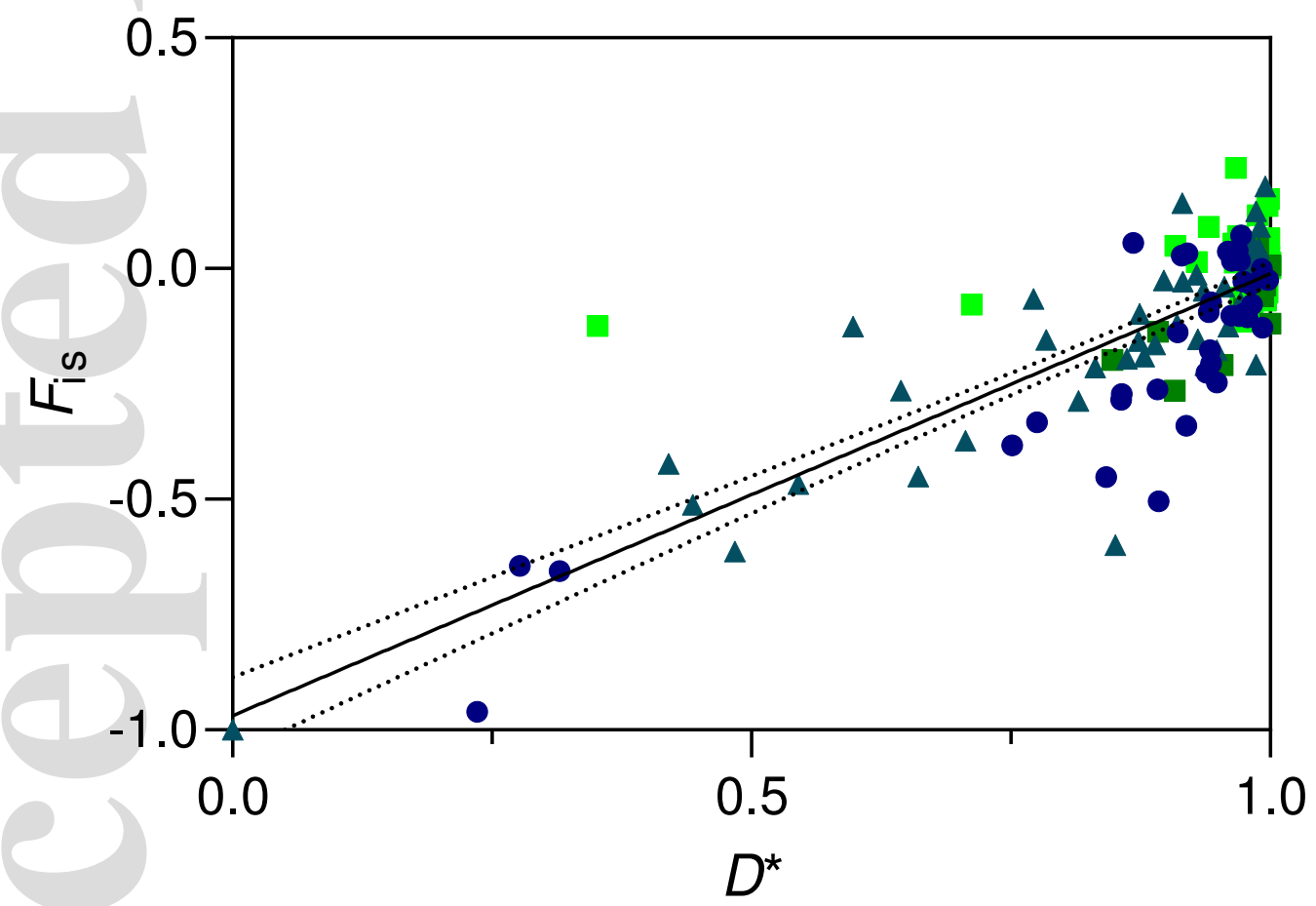

mec_15532_f3.eps 